ORIGINAL ARTICLE

\title{
Management of Liver Injuries: The Panamerican Trauma Society 2018 Consensus Guidelines
}

\author{
Gerd D Pust ${ }^{1}$, Pablo Ottolino², Tarek Razek ${ }^{3}$, Gregory Peck ${ }^{4}$
}

\begin{abstract}
Objective: The objective of this guideline is to create a framework and recommendations for best practice management of traumatic liver injuries in trauma patients cared for by surgeons in the Americas. The guidelines presented are based on an extensive literature review including international studies and data as well as in-depth consensus discussions at the 2018 Panamerican Trauma Society Liver Trauma Consensus session. Materials and methods: A PubMed literature review was performed including all relevant prospective, retrospective, meta-analysis studies, and guideline manuscripts between 1995 and 2018. Expert presentations, literature review, and guideline proposal discussions were completed at the liver trauma consensus session at the annual Panamerican Trauma Society meeting in Cartagena, Colombia 2018.

Results: The literature search revealed 32 relevant studies and manuscript as a foundation for the Panamerican Trauma Society Liver Trauma Management Guidelines. Expert discussions at the liver trauma consensus sessions added important aspects unique to clinical practice in rural and urban trauma centers in Latin American countries. The developed guidelines may contribute to a more standardized and evidence-based approach to the management of patients with liver trauma in the Americas.
\end{abstract}

Conclusion: Liver trauma consensus sessions and detailed literature review were effective in completing a Panamerican Trauma Society consensus guidelines manuscript for the management of patients with liver trauma. The guidelines may assist physicians in the provision of a standard and effective approach to the management of patients with liver trauma across the Americas with the intent to improve outcomes and outcomes measurement.

Keywords: Consensus guidelines, Liver trauma, Management of liver injuries, Nonoperative liver trauma, Operative liver trauma, The Panamerican Trauma Society 2018 Consensus Guidelines.

\section{RESUMEN}

Objetivo: El objetivo de estas pautas es crear una guía y recomendaciones para el manejo optimo de las lesiones hepáticas en pacientes traumatizados atendidos por cirujanos en las Américas. Las pautas presentadas se basan en una extensa revisión de la literatura que incluye estudios y datos internacionales, así como la discusión en profundidad en la sesión del Consenso de Trauma Hígado de la Sociedad Panamericana de Trauma del año 2018.

Materiales y métodos: se realizó una revisión de la literatura de PubMed que incluyó todos los estudios prospectivos, retrospectivos, metanálisis y manuscritos de pautas relevantes entre 1995 y 2018. Las presentaciones de expertos, la revisión de la literatura y las discusiones de propuestas de pautas se analizaron en la sesión de consenso sobre trauma hepático en el congreso anual de la Sociedad Panamericana de Trauma realizado en Cartagena, Colombia 2018.

Resultados: La búsqueda en la literatura reveló 32 estudios y manuscritos relevantes como base para las pautas en el Manejo del Trauma Hepático de la Sociedad Panamericana de Trauma. Las discusiones de expertos en las sesiones de consenso de trauma hepático agregaron aspectos importantes exclusivos de la práctica clínica en centros de trauma rural y urbano en países de América Latina. Las pautas desarrolladas pueden contribuir a un enfoque más estandarizado basado en la evidencia para el tratamiento de pacientes con trauma hepático en las Américas.

Conclusión: Las sesiones de consenso de trauma hepático y la revisión detallada de la literatura fueron efectivas para completar un manuscrito de pautas de la Sociedad Panamericana de Trauma para el tratamiento de pacientes con trauma hepático. Las siguientes pautas pueden ayudar a los médicos a adoptar un enfoque estándar y efectivo para el tratamiento de pacientes con trauma hepático en todo el continente americano con la intención de mejorar los resultados y la medición de los mismos.

Palabras clave: Manejo de lesiones hepáticas, Pautas de consenso, Pautas de consenso de la Sociedad Panamericana de Trauma 2018, Trauma hepático, Trauma hepático no quirúrgico, Traumatismo hepático operatorio.

Panamerican Journal of Trauma, Critical Care \& Emergency Surgery (2019): 10.5005/jp-journals-10030-1247

\section{INTRODUCTION}

Approximately 5.8 million people die annually as a result of trauma worldwide and tens of millions are injured. ${ }^{1}$ In the Americas, the injury death rate is between 55.4 and 74.1 deaths per 100.000 population. ${ }^{1}$ The liver is the most commonly injured organ in patients with abdominal trauma. ${ }^{2}$ Surgical management of patients with liver trauma varies among providers, healthcare systems, rural vs urban hospitals, and Panamerican Trauma Society member countries. The initial resuscitation and trauma care provided, available resources, and provider experience significantly affect
${ }^{1}$ Division of Trauma and Surgical Critical Care, The DeWitt Daughtry Family Department of Surgery, RyderTrauma Center/Jackson Memorial Hospital Miller School of Medicine University of Miami, Miami, Florida, USA

${ }^{2}$ Trauma and Emergency Unit, Dr. Sótero del Río Hospital, Santiago Metropolitan Región, Chile

${ }^{3}$ Department of Surgery, McGill University Health Centre, Montreal, Quebec, Canada

${ }^{4}$ Department of Surgery, Rutgers University, New Brunswick, New Jersey, USA

(c) The Author(s). 2019 Open Access This article is distributed under the terms of the Creative Commons Attribution 4.0 International License (https://creativecommons. org/licenses/by-nc/4.0/), which permits unrestricted use, distribution, and non-commercial reproduction in any medium, provided you give appropriate credit to the original author(s) and the source, provide a link to the Creative Commons license, and indicate if changes were made. The Creative Commons Public Domain Dedication waiver (http://creativecommons.org/publicdomain/zero/1.0/) applies to the data made available in this article, unless otherwise stated. 
outcomes, i.e., survival and morbidity in patients with complex liver trauma. Advanced resources, provider density and expertise are available at high-volume urban trauma centers. Access to trauma care at rural hospitals however, is often more challenging and yet, a large portion of patients with liver trauma receive initial care at rural hospitals. ${ }^{3}$ These Panamerican Trauma Society guidelines are intended to support decision making for physicians in an effort to provide consistent, high-quality trauma care in urban/ rural hospitals, intending to standardize care. These guidelines are the result of a combination of literature-based data review and consensus from a session discussion of trauma surgeon experts during the 2018 Panamerican Trauma Society meeting.

\section{Materials and Methods}

A PubMed literature search for "operative liver trauma," "nonoperative liver trauma," "operative liver injury," and "nonoperative liver injury" was performed including relevant prospective, retrospective, meta-analysis studies, and guideline manuscripts between 1995 and 2018. Expert presentations, literature review and guideline proposal discussions were completed at the liver trauma consensus session at the annual Panamerican Trauma Society meeting in Cartagena, Columbia 2018.

Literature grading systems and guideline development recommendations were evaluated using guidelines of the Agency for Healthcare Policy and Research. ${ }^{4}$ The GRADE system ${ }^{5-10}$ recognized by the World Health Organization was used to classify the level of evidence and weigh the recommendations in this guideline. This grading system classifies the quality of evidence in one of four levels: high, moderate, low, and very low. ${ }^{8}$ Although the GRADE system has its own limitations, ${ }^{7}$ we decided to use it to weigh recommendations within this guideline manuscript.

\section{Results}

The literature search revealed for the search term "operative liver trauma" 128 publications, for "operative liver injury" 183 publications, for "nonoperative liver trauma" 65 publications, and "nonoperative liver injury," 62 publications. Redundant studies were removed from the search list. After careful review of the literature search results, 32 publications (Table 1) were deemed of significance for this liver trauma consensus session and guideline development.

Relevant studies and existing management guidelines were presented and discussed during the 2018 liver trauma consensus session at the annual Panamerican Trauma Society meeting in Cartagena, Columbia. Expert and audience discussions were held to include region-specific adjustments, resource availability, and data for these Panamerican liver trauma consensus guidelines (Table 2).

\section{Liver Trauma_Initial Management Recommendations Level of Recommendation-High Quality}

- Patients with suspected liver injury secondary to blunt abdominal trauma presenting with hemodynamic instability and free fluid on abdominal focused assessment with sonography in trauma (FAST) examination should undergo emergency laparotomy. ${ }^{11-13}$

- Patients with suspected liver injury secondary to penetrating trauma with hemodynamic instability should undergo emergency laparotomy. ${ }^{12,13}$
Corresponding Author: Gerd D Pust, Division of Trauma and Surgical Critical Care, The DeWitt Daughtry Family Department of Surgery, Ryder Trauma Center/Jackson Memorial Hospital Miller School of Medicine University of Miami, Miami, Florida, USA, Phone: +1-305-5851822, e-mail: gpust@med.miami.edu

How to cite this article: Pust GD, Ottolino P, RazekT, et al. Management of Liver Injuries: The Panamerican Trauma Society 2018 Consensus Guidelines. Panam J Trauma Crit Care Emerg Surg 2019;8(3):133-138.

Source of support: Nil

Conflict of interest: None

Table 1: Level of recommendation definitions in the GRADE system ${ }^{8}$

\begin{tabular}{ll}
\hline Level of recommendation & Definition \\
\hline High quality & $\begin{array}{l}\text { Further research is very unlikely to } \\
\text { change our confidence in the estimate } \\
\text { of effect } \\
\text { Moderate quality }\end{array}$ \\
$\begin{array}{l}\text { Further research is likely to have an } \\
\text { important impact on our confidence in } \\
\text { the estimate of effect and may change } \\
\text { the estimate }\end{array}$ \\
$\begin{array}{l}\text { Further research is very likely to have } \\
\text { an important impact on our confidence } \\
\text { in the estimate of effect and is likely to } \\
\text { change the estimate } \\
\text { Any estimate of effect is very uncertain }\end{array}$ \\
\hline
\end{tabular}

Table 2: The American Association for the Surgery of Trauma organ injury classification for liver injuries ${ }^{18}$

\begin{tabular}{|c|c|c|}
\hline Grade & Type of injury & Description of injury \\
\hline \multirow[t]{2}{*}{ I } & Hematoma & Subcapsular, $<10 \%$ surface area \\
\hline & Laceration & Capsular tear, $<1 \mathrm{~cm}$ parenchymal depth \\
\hline \multirow[t]{2}{*}{ II } & Hematoma & $\begin{array}{l}\text { Subcapsular, } 10-50 \% \text { surface area } \\
\text { intraparenchymal }<10 \mathrm{~cm} \text { in diameter }\end{array}$ \\
\hline & Laceration & $\begin{array}{l}\text { Capsular tear } 1-3 \text { parenchymal depth, } \\
<10 \mathrm{~cm} \text { in length }\end{array}$ \\
\hline \multirow[t]{2}{*}{ III } & Hematoma & $\begin{array}{l}\text { Subcapsular, }>50 \% \text { surface area of } \\
\text { ruptured subcapsular or parenchymal } \\
\text { hematoma; intraparenchymal hema- } \\
\text { toma }>10 \mathrm{~cm} \text { or expanding }\end{array}$ \\
\hline & Laceration & $>3 \mathrm{~cm}$ parenchymal depth \\
\hline IV & Laceration & $\begin{array}{l}\text { Parenchymal disruption involving } \\
25-75 \% \text { hepatic lobe or } 1-3 \text { Couinaud's } \\
\text { segments }\end{array}$ \\
\hline \multirow[t]{3}{*}{ V } & Laceration & $\begin{array}{l}\text { Parenchymal disruption involving } \\
>75 \% \text { of hepatic lobe or }>3\end{array}$ \\
\hline & & $\begin{array}{l}\text { Couinaud's segments within a single } \\
\text { lobe }\end{array}$ \\
\hline & Vascular & $\begin{array}{l}\text { Juxtahepatic venous injuries; i.e, } \\
\text { retrohepatic vena cava/central major } \\
\text { hepatic veins }\end{array}$ \\
\hline VI & Vascular & Hepatic avulsion \\
\hline
\end{tabular}

- Patients with suspected liver injury secondary to blunt or penetrating trauma with clinical examination findings of peritonitis should undergo emergency laparotomy.

- Patients with suspected liver injury secondary to blunt or penetrating trauma with stable vital signs and absence of 
peritonitis should undergo further imaging studies with computed tomography $(\mathrm{CT}){ }^{12,14}$

\section{Level of Recommendation-Moderate Quality}

- Early activation of a massive transfusion protocol for patients with major hemorrhage from liver injury is advisable. ${ }^{15,16}$

- A thromboelastography and/or other laboratory coagulation parameter guided correction of coagulopathy in patients with hemorrhage from the liver injury are essential. ${ }^{17}$

- Liver injuries should be graded using the American Association for the Surgery of Trauma (AAST) organ injury classification. ${ }^{18}$

- Patients with AAST grade II or higher liver injuries should receive hemodynamic monitoring and monitoring for signs of bleeding in an intensive care unit setting. ${ }^{19}$

\section{Level of Recommendation-Low Quality}

- The use of resuscitative endovascular balloon occlusion of the aorta in patients with major liver hemorrhage and profound hemorrhagic shock should be considered until operative hepatic vascular isolation (e.g., Pringle maneuver) is achieved. ${ }^{20}$

\section{Operative Management of Liver Injuries}

\section{Level of Recommendation-High Quality}

- Perihepatic packing with surgical sponges is the initial operative maneuver to control venous hepatic bleeding.,13

- A Pringle maneuver ${ }^{21}$ should be performed if arterial and/or portal venous bleeding is present. ${ }^{13,22,23}$

- Direct hepatorrhaphy of the liver lacerations with 2-0 or 0 absorbable suture, e.g., chromic with a blunt-tipped needle may control hemorrhage from liver laceration surfaces. ${ }^{22}$

- Direct manual compression of liver parenchyma over large lacerations can assist in initial hemorrhage control. ${ }^{22}$

- If perihepatic packing controls retrohepatic hemorrhage, maintain packing in place for $24-48$ hours prior to reexploration and possible surgical repair of hepatic veins or retrohepatic vena cava.

- If perihepatic packing and Pringle maneuver fail to control retrohepatic bleeding, proceed with the mobilization of the liver and total vascular exclusion by control of infrahepatic and suprahepatic vena cava. ${ }^{22}$

- Activate massive transfusion protocol early in patients with major hemorrhage from liver injuries.

- Use 1:1:1 packed red blood cells—fresh frozen plasma—platelets or whole blood transfusion regimens.

\section{Level of Recommendation-Moderate Quality}

- Formal anatomic liver resections in the setting of trauma are not frequently required. ${ }^{22}$

- Direct suture ligation or clipping of intrahepatic vascular structures may assist in the control of hemorrhage. ${ }^{22}$

- Finger fracture technique with suture ligation or clipping of intrahepatic vascular structures may assist in exposure on intrahepatic bleeding vessels. ${ }^{22}$

- Balloon tamponade of bleeding transhepatic missile tracks is an effective tool for hemorrhage control. ${ }^{24}$

- Intraoperative or postoperative interventional radiology angioembolization is effective in controlling arterial intraparenchymal hemorrhage. ${ }^{25}$
- Selective ligation of the left or right hepatic artery for control of life threating hemorrhage is a possible life saving option, however is associated with significant necrosis of the affected liver lobe. ${ }^{22}$

- Hepatic artery injuries require reconstruction. Initial shunt placement is a viable option in a damage control mode. Small lacerations may be repaired primarily or with a vein patch. Segmental defects and loss of length require a tension-free repair with a reversed vein interposition graft.

- Portal vein juries require reconstruction. Initial shunt placement is a viable option in a damage control mode. Small lacerations may be repaired primarily or with a vein patch. Segmental defects and loss of length require a tension-free repair with a reversed vein interposition graft.

- Bile duct injuries require reconstruction. In a damage control mode, drain placement (e.g., T-tube) into the transected bile duct will control bile flow. Subsequent reconstruction with a roux-en-Y choledchojejunostomy is required. Small defects can be repaired primarily if narrowing or tension can be avoided.

- Placement of closed suction drain for large liver lacerations is recommended to control a potential bile leak. ${ }^{22}$

- Hepatorrhaphy with an omental pedicle patch may assist in hemostasis. $^{26}$

- Hemostasis from superficial liver capsule bleeding may be achieved with electro-cautery or argon beam.

- Topical hemostatic agents (e.g., fibrin glue and kaolin) may assist in hemostasis of superficial liver capsule and surface bleeding.

\section{Level of Recommendation-Low Quality}

- Endovascular balloon occlusion of infra and suprahepatic vena cava is an effective alternative to external control of vena cava in the setting of total vascular hepatic exclusion.

- In rare circumstances of a patient with AAST grade VI liver injury (complete avulsion and destruction of the liver), orthotopic liver transplantation within 24-48 hours after vascular shunting can be a lifesaving intervention. ${ }^{22,27,28}$

\section{Nonoperative Management of Liver Injuries Level of Recommendation-High Quality}

- Patients with liver injuries from blunt trauma and normal vital signs and absence of peritonitis can be managed nonoperatively. ${ }^{12,29-32}$

- CT scan with intravenous contrast should be obtained to evaluate the extent of liver injury to establish if active contrast extravasation (contrast blush) or a pseudoaneurysm is present, and to classify the AAST injury grade. ${ }^{12,33,34}$

- Patients with a significant contrast blush, i.e., the presence of active arterial bleeding or a pseudoaneurysm, should undergo angioembolization. ${ }^{25,33,34}$

- Patients with AAST grade II or higher liver injuries should receive hemodynamic monitoring and monitoring for signs of bleeding in an intensive care unit setting. ${ }^{19}$

\section{Level of Recommendation-Moderate Quality}

- Patients with the unexplained drop in hemoglobin, abdominal pain, jaundice, or persistent systemic inflammatory response syndrome, should be evaluated with repeat by CT scan. ${ }^{8}$

- Patients with liver injuries AAST grades IV and V may benefit from interval follow-up imaging with ultrasound, contrasts enhanced 
ultrasound, or CT scan to evaluate for possible subsequent pseudoaneurysm or biloma formation during index hospital admission. $^{35}$

- Patients with initial or delayed presentation of hemobilia require angiography of the liver and possible embolization of the feeding arterial brunch.

\section{Management of Bile Leaks after Liver Injuries Level of Recommendation-High Quality}

- Patients with extrahepatic bile duct injuries, including common bile duct, common hepatic duct, left, and/or right hepatic ducts require subsequent primary repair or reconstruction with choledochojejunostomy.

\section{Level of Recommendation-Moderate Quality}

- Extrahepatic bile duct injury may be controlled with shunt or drain placement during the initial trauma damage control laparotomy phase, followed by subsequent definitive reconstruction.

- A perihepatic closed suction drain placement after operative hepatorrhaphy for AAST grade II and greater liver lacerations is recommended.

- Patients with persistent bile leak and drain output between 200 and $500 \mathrm{~mL}$ daily over an extended period of time (10-14 days) may undergo endoscopic retrograde cholangiography pancreatography, sphincterotomy, and a placemat of a temporary, removable plastic ductal stent. ${ }^{36}$

- Injury to the gallbladder is treated with cholecystectomy.

\section{Transfer of Patients with Liver Injuries to Higher Level of Care Facilities}

\section{Level of Recommendation-Moderate Quality}

- Patients with liver injuries and hemorrhagic shock located in remote rural hospitals or nontrauma center hospitals should undergo emergency damage control laparotomy, perihepatic packing, and hemorrhage control prior to transfer to the trauma center.

- Patients with liver injuries AAST grade II or greater located at a rural hospital or nontrauma center hospital should be transferred to a trauma center once hemodynamically stable, i.e., resuscitation achieved.

- Final decision on the requirement for transfer, and evaluation of the patient's status, and hemodynamic stability allowing for transfer is the responsibility of the referring/treating physician present at the patient site.

\section{Discussion}

A comprehensive literature search and consensus discussion at the 2018 Panamerican Trauma Society meeting in Cartagena, Colombia resulted in the Panamerican Trauma Society Management of Liver Injury Guidelines, optimized for providers in the Panamerican region, i.e., the Americas. The guidelines are structured in five main segments: liver trauma initial management recommendations, operative management of liver injuries, nonoperative management of liver injuries, management of bile leaks after liver injuries, and transfer of patients with liver injuries to a higher level of care facilities (Table 3).

Table 3: Literature recommended for further review

\begin{tabular}{|c|c|c|c|}
\hline Author & Title & Journal & Year \\
\hline Anand et al. ${ }^{36}$ & $\begin{array}{l}\text { Endoscopic retrograde cholangiopancreatography is an effective treatment for } \\
\text { bile leak after severe liver trauma. }\end{array}$ & JTrauma & 2011 \\
\hline Arora et al. ${ }^{26}$ & Pedicled omentum hepatorrhaphy in blunt hepatic trauma & Int Surg J & 2017 \\
\hline Asensio et al. ${ }^{37}$ & $\begin{array}{l}\text { Multidisciplinary approach for the management of complex hepatic injuries } \\
\text { AAST- Organ Injury Scale (OIS) grades IV-V: a prospective study }\end{array}$ & Scand J Surg & 2007 \\
\hline Asensio et al. ${ }^{38}$ & $\begin{array}{l}\text { Operative management and outcomes in } 103 \text { AAST-OIS grades IV and V complex } \\
\text { hepatic injuries: trauma surgeons still need to operate, but angioembolization } \\
\text { helps }\end{array}$ & JTrauma & 2003 \\
\hline Ball et al. ${ }^{24}$ & $\begin{array}{l}\text { A decade's experience with balloon catheter tamponade for the emergency } \\
\text { control of hemorrhage }\end{array}$ & JTrauma & 2011 \\
\hline Boese et al. ${ }^{29}$ & Nonoperative management of blunt hepatic trauma: a systematic review & JTrauma Acute Care Surg & 2015 \\
\hline Boone et al. ${ }^{11}$ & $\begin{array}{l}\text { Evolution of management of major hepatic trauma: identification of patterns of } \\
\text { injury }\end{array}$ & JTrauma & 1995 \\
\hline Brenner et al. ${ }^{20}$ & $\begin{array}{l}\text { Resuscitative endovascular balloon occlusion of the aorta and resuscitative } \\
\text { thoracotomy in select patients with hemorrhagic shock: early results from the } \\
\text { American Association for the surgery of trauma's aortic occlusion in resuscitation } \\
\text { for trauma and acute care surgery registry }\end{array}$ & J Am Coll Surg & 2018 \\
\hline Cirocchi et al. ${ }^{30}$ & $\begin{array}{l}\text { Non-operative management vs operative management in high-grade blunt } \\
\text { hepatic injury }\end{array}$ & Cochrane Database Syst Rev & 2015 \\
\hline Coccolini et al. ${ }^{31}$ & WSES classification and guidelines for liver trauma & World J Emerg Surg & 2016 \\
\hline Como et al. ${ }^{14}$ & $\begin{array}{l}\text { Practice management guidelines for selective nonoperative management of } \\
\text { penetrating abdominal trauma }\end{array}$ & J Trauma & 2010 \\
\hline Croce et al. ${ }^{32}$ & $\begin{array}{l}\text { Nonoperative management of blunt hepatic trauma is the treatment of choice for } \\
\text { hemodynamically stable patients. Results of a prospective trial }\end{array}$ & Ann Surg & 1995 \\
\hline
\end{tabular}


Contd...

\begin{tabular}{|c|c|c|c|}
\hline Author & Title & Journal & Year \\
\hline Di Saverio et al. $^{5}$ & $\begin{array}{l}\text { Predictive factors of morbidity and mortality in grades IV and } V \text { liver trauma un- } \\
\text { dergoing perihepatic packing: single institution } 14 \text { years experience at European } \\
\text { trauma center }\end{array}$ & Injury & 2012 \\
\hline Fingerhut et al. ${ }^{22}$ & $\begin{array}{l}\text { Surgical management of liver injuries in adults_current indications and pitfalls } \\
\text { of operative and non-operative policies: a review }\end{array}$ & Eur J Surg & 2000 \\
\hline Feliciano et al. $^{2}$ & Management of 1000 consecutive cases of hepatic trauma (1979-1984) & Ann Surg & 1986 \\
\hline Green et al. ${ }^{25}$ & $\begin{array}{l}\text { Outcomes and complications of angioembolization for hepatic trauma: a system- } \\
\text { atic review of the literature }\end{array}$ & J Trauma Acute Care Surg & 2016 \\
\hline Kozar et al. ${ }^{13}$ & $\begin{array}{l}\text { Western Trauma Association/critical decisions in trauma: operative management } \\
\text { of adult blunt hepatic trauma }\end{array}$ & JTrauma & 2011 \\
\hline Kozar et al. ${ }^{12}$ & $\begin{array}{l}\text { Western Trauma Association critical decisions in trauma: nonoperative manage- } \\
\text { ment of adult blunt hepatic trauma }\end{array}$ & J Trauma & 2009 \\
\hline Kutcher et al. ${ }^{33}$ & $\begin{array}{l}\text { The role of computed tomographic scan in ongoing triage of operative hepatic } \\
\text { trauma: a Western Trauma Association multicenter retrospective study }\end{array}$ & J Trauma Acute Care Surg & 2015 \\
\hline Man et al. ${ }^{23}$ & $\begin{array}{l}\text { Tolerance of the liver to intermittent pringle maneuver in hepatectomy for liver } \\
\text { tumors }\end{array}$ & Arch Surg & 1999 \\
\hline Melloul et al. ${ }^{34}$ & $\begin{array}{l}\text { Management of severe blunt hepatic injury in the era of computed tomography } \\
\text { and transarterial embolization: a systematic review and critical appraisal of the } \\
\text { literature }\end{array}$ & J Trauma Acute Care Surg & 2015 \\
\hline Moore et al. ${ }^{18}$ & OIS: spleen and liver (1994 revision) & J Trauma & 1995 \\
\hline Notrica et al. ${ }^{39}$ & $\begin{array}{l}\text { Nonoperative management of blunt liver and spleen injury in children: evalua- } \\
\text { tion of the ATOMAC guideline using GRADE }\end{array}$ & J Trauma Acute Care Surg & 2015 \\
\hline Patrono et al. ${ }^{28}$ & $\begin{array}{l}\text { Liver transplantation after severe hepatic trauma: a sustainable practice. A single- } \\
\text { center experience and review of the literature }\end{array}$ & Clin Transplant & 2013 \\
\hline Peitzman et al. ${ }^{40}$ & Advanced operative techniques in the management of complex liver injury & J Trauma Acute Care Surg & 2012 \\
\hline Perumean et al. ${ }^{19}$ & Low-grade blunt hepatic injury and benefits of intensive care unit monitoring & Am J Surg & 2017 \\
\hline Pringle ${ }^{21}$ & Notes on the arrest of hepatic hemorrhage due to trauma. & Ann Surg & 1908 \\
\hline Ribeiro Jr et al. ${ }^{27}$ & Liver transplantation after severe hepatic trauma: current indications and results & Arq Bras Cir Dig & 2015 \\
\hline Schnuriger ${ }^{41}$ & $\begin{array}{l}\text { Current practice and the role of the } \mathrm{CT} \text { in the management of penetrating liver } \\
\text { injuries at a level I trauma center }\end{array}$ & J Emerg Trauma Shock & 2011 \\
\hline Stassen et al. ${ }^{35}$ & $\begin{array}{l}\text { Nonoperative management of blunt hepatic injury: an Eastern } \\
\text { Association for the Surgery of Trauma practice management guideline }\end{array}$ & J Trauma Acute Care Surg & 2012 \\
\hline Ward et al. ${ }^{42}$ & Management of blunt liver injury: what is new? & Eur J Trauma Emerg Surg & 2015 \\
\hline West et al. ${ }^{4}$ & Systems to rate the strength of scientific evidence & $\begin{array}{l}\text { Evid Rep Technol Assess } \\
\text { (Summ) }\end{array}$ & 2002 \\
\hline
\end{tabular}

The goal of this guideline is to standardize the medical care and operative approach to patients with liver injuries based on research data, literature review, expert opinion, and consensus discussion. These guidelines can assist providers in the decision making process caring for patients with liver trauma. Furthermore, it can serve as an educational tool for emergency room physicians and surgeons in training and providers not frequently caring for patients with complex liver injuries.

Consensus conference meetings are an effective tool to appraise relevant research data and literature sources as well as discuss current practice standards to summarize them into society's clinical practice guidelines.

Nonoperative, operative, and critical care management of trauma patients with liver injuries and other associated injuries is complex and challenging. A combination of standardized practice guideline-oriented care, provider expertise, and consideration of resources at a particular trauma center or rural hospital may reduce mortality and morbidity associated with liver injuries. The above will ultimately assist in outcome measurement in the Americas.

\section{References}

1. Organization WH. Injuries and violence: the facts. https:// wwwwhoint/violence_injury_prevention/key_facts/en/, 2010.

2. Feliciano DV, Mattox KL, Jordan Jr GL, et al. Management of 1000 consecutive cases of hepatic trauma (1979-1984). Ann Surg 1986;204(4):438-445. DOI: 10.1097/00000658-198610000-00012.

3. Newgard CD, Fu R, Bulger E, et al. Evaluation of rural vs urban trauma patients served by 9-1-1 emergency medical services. JAMA Surg 2017;152(1):11-18. DOI: 10.1001/jamasurg.2016.3329.

4. West S, King V, Carey TS, et al. Systems to rate the strength of scientific evidence. Evid Rep Technol Assess (Summ) 2002;47:1-11.

5. Di Saverio S, Catena F, Filicori F, et al. Predictive factors of morbidity and mortality in grade IV and $\mathrm{V}$ liver trauma undergoing perihepatic packing: single institution 14 years experience at European trauma centre. Injury 2012;43(9):1347-1354. DOI: 10.1016/j.injury.2012.01.003.

6. Atkins $D$, Briss PA, Eccles $M$, et al. Systems for grading the quality of evidence and the strength of recommendations II: pilot study of a new system. BMC Health Serv Res 2005;5(1):25. DOI: 10.1186/14726963-5-25.

7. Kavanagh BP. The GRADE system for rating clinical guidelines. PLoS Med 2009;6(9):e1000094. DOI: 10.1371/journal.pmed.1000094. 
8. Guyatt GH, Oxman AD, Vist GE, et al. GRADE: an emerging consensus on rating quality of evidence and strength of recommendations. BMJ 2008;336(7650):924-926. DOI: 10.1136/bmj.39489.470347.AD.

9. Alonso-Coello P, Oxman AD, Moberg J, et al. GRADE evidence to decision (EtD) frameworks: a systematic and transparent approach to making well informed healthcare choices. 2: clinical practice guidelines. Gac Sanit 2018;32(2):167.e1-167.e10. DOI: 10.1016/j.gaceta. 2017.03.008.

10. Alonso-CoelloP, Oxman AD, Moberg J, etal.GRADEevidence to decision (EtD) frameworks: a systematic and transparent approach to making well informed healthcare choices. 2: clinical practice guidelines. BMJ 2016;353:i2089. DOI: 10.1136/bmj.i2089.

11. Boone DC, Federle M, Billiar TR, et al. Evolution of management of major hepatic trauma: identification of patterns of injury. J Trauma 1995;39(2):344-350. DOI: 10.1097/00005373-199508000-00026.

12. Kozar RA, Moore FA, Moore EE, et al. Western Trauma Association critical decisions in trauma: nonoperative management of adult blunt hepatic trauma. J Trauma 2009;67(6):1144-1148. ; discussion 8-9 10.1097/TA.0b013e3181ba361f.

13. Kozar RA, Feliciano DV, Moore EE, et al. Western Trauma Association/ critical decisions in trauma: operative management of adult blunt hepatic trauma. J Trauma 2011;71(1):1-5. DOI: 10.1097/ TA.0b013e318220b192.

14. Como JJ, Bokhari F, Chiu WC, et al. Practice management guidelines for selective nonoperative management of penetrating abdominal trauma. J Trauma 2010;68(3):721-733. DOI: 10.1097/ TA.0b013e3181cf7d07.

15. Hwang K, Kwon J, Cho J, et al. Implementation of trauma center and massive transfusion protocol improves outcomes for major trauma patients: a study at a single institution in Korea. World J Surg 2018;42(7):2067-2075. DOI: 10.1007/s00268-017-4441-5.

16. Meyer DE, Vincent LE, Fox EE, et al. Every minute counts: time to delivery of initial massive transfusion cooler and its impact on mortality. J Trauma Acute Care Surg 2017;83(1):19-24. DOI: 10.1097/ TA.0000000000001531.

17. Prat NJ, Meyer AD, Ingalls NK, et al. Rotational thromboelastometry significantly optimizes transfusion practices for damage control resuscitation in combat casualties. J Trauma Acute Care Surg 2017;83(3):373-380. DOI: 10.1097/TA.0000000000001568.

18. Moore EE, Cogbill TH, Jurkovich GJ, et al. Organ injury scaling: spleen and liver (1994 revision). J Trauma 1995;38(3):323-324. DOI: 10.1097/00005373-199503000-00001.

19. Perumean JC, Martinez M, Neal R, et al. Low-grade blunt hepatic injury and benefits of intensive care unit monitoring. Am J Surg 2017;214(6):1188-1192. DOI: 10.1016/j.amjsurg.2017.09.003.

20. Brenner M, Inaba K, Aiolfi A, et al. Resuscitative endovascular balloon occlusion of the aorta and resuscitative thoracotomy in select patients with hemorrhagic shock: early results from the American Association for the Surgery of Trauma's Aortic Occlusion in resuscitation for trauma and acute care surgery registry. J Am Coll Surg 2018;226(5):730-740. DOI: 10.1016/j.jamcollsurg.2018.01.044.

21. Pringle J. Notes on the arrest of hepatic hemorrhage due to trauma. Ann Surg 1908;48(4):541-549. DOI: 10.1097/00000658-19081000000005.

22. Fingerhut A, Trunkey D. Surgical management of liver injuries in adults - current indications and pitfalls of operative and nonoperative policies: a review. Eur J Surg 2000;166(9):676-686. DOI: 10.1080/110241500750008411.

23. Man K, Fan ST, Ng IO, et al. Tolerance of the liver to intermittent pringle maneuver in hepatectomy for liver tumors. Arch Surg 1999;134(5):533-539. DOI: 10.1001/archsurg.134.5.533.

24. Ball CG, Wyrzykowski AD, Nicholas JM, et al. A decade's experience with balloon catheter tamponade for the emergency control of hemorrhage. J Trauma 2011;70(2):330-333. DOI: 10.1097/TA.0b013e318203285c.

25. Green CS, Bulger EM, Kwan SW. Outcomes and complications of angioembolization for hepatic trauma: a systematic review of the literature. J Trauma Acute Care Surg 2016;80(3):529-537. DOI: 10.1097/ TA.0000000000000942.

26. Arora BK, Arora R, Arora A. Pedicled omentum hepatorrhaphy in blunt hepatic trauma. Int Surg J 2017;4(9):3038-3042. DOI: 10.18203/23492902.isj20173883.

27. Ribeiro Jr MA, Medrado MB, Rosa OM, et al. Liver transplantation after severe hepatic trauma: current indications and results. Arq Bras Cir Dig 2015;28(4):286-289. DOI: 10.1590/s0102-6720201500040017.

28. Patrono D, Brunati $A$, Romagnoli $R$, et al. Liver transplantation after severe hepatic trauma: a sustainable practice. A singlecenter experience and review of the literature. Clin Transplant 2013;27(4):E528-E537. DOI: 10.1111/ctr.12192.

29. Boese CK, Hackl M, Muller LP, et al. Nonoperative management of blunt hepatic trauma: a systematic review. J Trauma Acute Care Surg 2015;79(4):654-660. DOI: 10.1097/TA.0000000000000814.

30. Cirocchi R, Trastulli S, Pressi E, et al. Non-operative management versus operative management in high-grade blunt hepatic injury. Cochrane Database Syst Rev 2015;8:CD010989. DOI: 10.1002/14651858.CD010989.pub2.

31. Coccolini F, Catena F, Moore EE, et al. WSES classification and guidelines for liver trauma. World J Emerg Surg 2016;11:50. DOI: 10.1186/s13017-016-0105-2.

32. Croce MA, Fabian TC, Menke PG, et al. Nonoperative management of blunt hepatic trauma is the treatment of choice for hemodynamically stable patients. Results of a prospective trial. Ann Surg 1995;221(6):744753. ; discussion 53-55 10.1097/00000658-199506000-00013.

33. Kutcher ME, Weis JJ, Siada SS, et al. The role of computed tomographic scan in ongoing triage of operative hepatic trauma: a Western Trauma Association multicenter retrospective study. J Trauma Acute Care Surg 2015;79(6):951-956. ; discussion 6 10.1097/TA.0000000000000692.

34. Melloul E, Denys A, Demartines N. Management of severe blunt hepatic injury in the era of computed tomography and transarterial embolization: a systematic review and critical appraisal of the literature. J Trauma Acute Care Surg 2015;79(3):468-474. DOI: 10.1097/ TA.0000000000000724.

35. Stassen NA, Bhullar I, Cheng JD, et al. Nonoperative management of blunt hepatic injury: an Eastern Association for the Surgery of Trauma practice management guideline. J Trauma Acute Care Surg 2012;73(5 Suppl 4):S288-S293. DOI: 10.1097/TA.0b013e318270160d.

36. Anand RJ, Ferrada PA, Darwin PE, et al. Endoscopic retrograde cholangiopancreatography is an effective treatment for bile leak after severe liver trauma. J Trauma 2011;71(2):480-485. DOI: 10.1097/ TA.0b013e3181efc270.

37. Asensio JA, Petrone P, Garcia-Nunez L, et al. Multidisciplinary approach for the management of complex hepatic injuries AAST-OIS grades IV-V: a prospective study. Scand J Surg 2007;96(3):214-220. DOI: $10.1177 / 145749690709600306$.

38. Asensio JA, Roldan G, Petrone P, et al. Operative management and outcomes in 103 AAST-OIS grades IV and V complex hepatic injuries: trauma surgeons still need to operate, but angioembolization helps. J Trauma 2003;54(4):647-653. ; discussion 53-54 10.1097/01. TA.0000054647.59217.BB.

39. Notrica DM, Eubanks 3rd JW, Tuggle DW, et al. Nonoperative management of blunt liver and spleen injury in children: evaluation of the ATOMAC guideline using GRADE. J Trauma Acute Care Surg 2015;79(4):683-693. DOI: 10.1097/TA.0000000000000808.

40. Peitzman AB, Marsh JW. Advanced operative techniques in the management of complex liver injury. J Trauma Acute Care Surg 2012;73(3):765-770. DOI: 10.1097/TA.0b013e318265cef5.

41. Schnuriger $B$, Talving $P$, Barbarino $R$, et al. Current practice and the role of the $C T$ in the management of penetrating liver injuries at a level I trauma center. J Emerg Trauma Shock 2011;4(1):53-57. DOI: 10.4103/0974-2700.76838.

42. Ward J, Alarcon L, Peitzman AB. Management of blunt liver injury: what is new? Eur J Trauma Emerg Surg 2015;41(3):229-237. DOI: 10.1007/s00068-015-0521-0. 